\title{
Comparison of HMF Hydrodeoxygenation over Different Metal Catalysts in a Continuous Flow Reactor
}

\author{
Jing Luo ${ }^{\mathrm{a}}$, Lisandra Arroyo-Ramírez ${ }^{\mathrm{a}}$, Jifeng Wei ${ }^{\mathrm{a}}$, Hongseok Yun ${ }^{\mathrm{b}}$, Christopher B. Murray ${ }^{\mathrm{b}}$ \\ and Raymond J. Gorte ${ }^{\mathrm{a}, *}$ \\ ${ }^{a}$ Department of Chemical \& Biomolecular Engineering, University of Pennsylvania \\ ${ }^{\mathrm{b}}$ Department of Chemistry, University of Pennsylvania \\ Philadelphia, PA 19104, United States
}

\begin{abstract}
The three-phase hydrodeoxygenation (HDO) of 5-hydroxymethylfurfural (HMF) and hydrogenation of 2,5-dimethylfuran (DMF) were studied over six carbon-supported metal catalysts (Pt, Pd, Ir, Ru, Ni, and $\mathrm{Co}$ ) using a tubular flow reactor with 1-propanol solvent, at $180^{\circ} \mathrm{C}$ and 33 bar. By varying the space time in the reactor, the reaction of $\mathrm{HMF}$ is shown to be sequential, with HMF reacting first to furfuryl ethers and other partially hydrogenated products, which then form 2,5-dimethylfuran (DMF). Ring-opened products and 2,5-

dimethyltetrahydrofuran (DMTHF) were produced only from reaction of DMF. Rate constants for the pseudo-first-order sequential reactions were obtained for each of the metals. The selectivities for the reaction of DMF varied with the metal catalyst, with Pd forming primarily DMTHF, Ir forming a mixture of DMTHF and open-ring products, and the other metals forming primarily open-ring products. Catalyst stabilities followed the order $\mathrm{Pt} \sim \mathrm{Ir}>\mathrm{Pd}>\mathrm{Ni}>\mathrm{Co}>\mathrm{Ru}$. Since the stability order correlated with carbon balances in the product $(>93 \%$ for Pt; $<75 \%$ for $\mathrm{Ru}$ ), deactivation appears to be caused by deposition of humins on the catalyst.
\end{abstract}

Keywords: 5-hydroxymethylfurfural, hydrodeoxygenation, dimethyl furan, continuous flow reactor, metal catalyst 
E-mails:

jingluo@seas.upenn.edu

gorte@ seas.upenn.edu

Address:

Department of Chemical and Biomolecular Engineering, University of Pennsylvania,

311A Towne Building, 220 S. $33^{\text {rd }}$ Street,

Philadelphia, PA 19104, USA

Phone: $215-898-8351$

Fax: 215-573-2093

*Corresponding Author:

Raymond J. Gorte

gorte@seas.upenn.edu 


\section{Introduction}

Hydrodeoxygenation (HDO) of 5-hydroxymethylfurfural (HMF) to 2,5-dimethylfuran

(DMF) has received a great deal of attention in the past few years because of its importance for converting biomass into petrochemical replacements. HMF can be produced by dehydration of glucose in reasonably high yields [1-3] but remains too reactive and unstable for use as a fuel. The amount of expensive $\mathrm{H}_{2}$ required to convert $\mathrm{HMF}$ to DMF is relatively small compared to what would be required for conversion of HMF to alkanes. DMF appears to have very good properties as a blending component for gasoline [4] and can also be converted to p-xylene by reaction with ethylene [5].

While a number of groups have reported high yields for the reaction of HMF to DMF [67], there are very large variations in the reported selectivities, sometimes for what appear to be nearly the same catalyst and reaction conditions. For example, Hu, et al. [6] reported yields to DMF as high as $95 \%$ for the reaction of $\mathrm{HMF}$ with $\mathrm{H}_{2}$ using a $\mathrm{Ru} / \mathrm{C}$ catalyst in tetrahydrofuran (THF); but Saha et al. [8] achieved only a 3\% DMF yield using the similar catalyst and solvent. In another example, it has been reported that Pt catalysts are not selective for the production of DMF due formation of over-hydrogenated products, with some studies showing selectivities as low as $10 \%$ [7]. However, in recent work from our laboratory [9], yields as high as $60 \%$ were obtained on a $\mathrm{Pt} / \mathrm{C}$ catalyst.

Determining the intrinsic selectivity for this reaction over a particular catalyst is complicated by the fact that it is a three-phase reaction (gas-phase $\mathrm{H}_{2}$; liquid-phase $\mathrm{HMF}, \mathrm{DMF}$, and solvent; solid catalyst) which is usually carried out in a semi-batch reactor. Diffusion of $\mathrm{H}_{2}$ to the catalyst surface is likely to be the rate-limiting step for most conditions. The catalyst volume is also typically a small fraction of the liquid volume, necessitating residence times on the order of hours in order to achieve high conversions. This means that initially formed products can undergo secondary reactions that in turn complicate analysis of the product selectivities [9]. Catalyst stability is also difficult to study in these systems.

In recent work from our laboratory, the reaction of HMF to DMF was studied over a Pt/C catalyst in both semi-batch and tubular flow reactors, under similar pressure and temperature conditions [9]. In agreement with previous reports that suggested Pt is a poor catalyst for this reaction, the selectivity to DMF was very low under semi-batch conditions. However, reasonable selectivities and yields could be obtained in the tubular flow reactor. By varying the residence 
time in the flow reactor, it was possible to show that the initial hydrogenation occurred on the carbonyl and alcohol functionalities, ultimately forming DMF. DMF itself could be considered an intermediate product that was further converted to open-ring and hydrogenated-ring products at longer space times. Therefore, the reaction network over $\mathrm{Pt} / \mathrm{C}$ should be considered sequential, with all products going through DMF. The high selectivities in the flow reactor were possible because the reactant contact time was on the order of minutes. Poor selectivity was observed in the semi-batch reactor because DMF was further converted.

The flow reactor also provided a convenient method for characterizing catalytic performance. By changing the flow rate and the catalyst loading, it was possible to vary the contact time by nearly two orders of magnitude, allowing measurement of the pseudo-first-order rate constants for the reaction network under steady-state conditions, with various solvents and at different temperatures. Obviously, the fact that this is a three-phase reaction makes a detailed understanding of these rate constants complicated; however, the rate constants do allow quantitative comparisons of different reactor conditions and different catalysts. Rates of catalyst deactivation could be easily monitored by following the conversion and selectivity as a function of time.

In the present work, we set out to compare the reaction of HMF to DMF over a series of carbon-supported catalysts, including $\mathrm{Pt}, \mathrm{Ir}, \mathrm{Pd}, \mathrm{Ni}, \mathrm{Co}$, and $\mathrm{Ru}$. These metals were chosen because they are all good hydrogenation catalysts, which have been shown to exhibit a wide range of selectivities for this reaction. All the reactions were performed using 1-propanol as the solvent, at a $180^{\circ} \mathrm{C}$ and 33 bar pressure. Interestingly, the overall reaction network was found to be similar with all six metals in that DMF is an intermediate product. The six metals do show variations in the rates for each of the reaction steps, different selectivities for over-hydrogenated products formed from DMF, and different rates of deactivation.

\section{Experimental}

The catalysts were all prepared in our lab using carbon black (Vulcan $\mathrm{XC}-72 \mathrm{R}$ ) as the support and all had 10-wt\% metal loadings. The metals were added to the support by impregnation, using a water/ethanol (5:1) solution of tetraammineplatinum (II) nitrate $\left(\mathrm{Pt}\left(\mathrm{NH}_{3}\right)_{4}\left(\mathrm{NO}_{3}\right)_{2}, 99.99 \%\right.$, Alfa Aesar), tetraamminepalladium(II) nitrate solution, $\left(\mathrm{Pd}\left(\mathrm{NH}_{3}\right)_{4}\left(\mathrm{NO}_{3}\right)_{2}, 99.9 \%\right.$, Alfa Aesar), cobalt(II) nitrate hexahydrate $\left(\mathrm{Co}\left(\mathrm{NO}_{3}\right)_{2} \cdot 6 \mathrm{H}_{2} \mathrm{O}, 99 \%\right.$, 
Aldrich), ruthenium(III) nitrosylnitrate solution, $\left(\mathrm{N}_{4} \mathrm{O}_{10} \mathrm{Ru}\right.$, Alfa Aesar), or iridium(III) chloride hydrate $\left(\mathrm{Cl}_{3} \mathrm{Ir} \cdot \mathrm{xH}_{2} \mathrm{O}\right.$, Aldrich). The dried powders were reduced by flowing a $5 \% \mathrm{H}_{2} / \mathrm{He}$ mixture over the catalysts while ramping the temperature at $2^{\circ} \mathrm{C} \mathrm{min}^{-1}$ to $400^{\circ} \mathrm{C}$, followed by heating to $500^{\circ} \mathrm{C}$ with heating ramp of $1^{\circ} \mathrm{C} \mathrm{min}^{-1}$. The catalysts were then held at this temperature for $2 \mathrm{~h}$. The catalysts were then placed in the flow reactor. We attempted to measure metal dispersions by selective chemisorption but found the results to be unreliable, in agreement with another recent report for carbon-supported metals [10]; therefore, TEM measurements were performed on each of the catalysts used in this study, with results shown in the Supplemental Materials section, Figures S1 to S6.

The reaction of $\mathrm{HMF}$ with $\mathrm{H}_{2}$ was carried out in the high-pressure, flow reactor that has been described in detail elsewhere [9]. The tubular reactor was a 20-cm long, stainless-steel tube with a 4.6-mm ID and 1/4-inch OD, passed through a tube furnace. The liquid feed, a mixture of 1g HMF (99\%, Sigma-Aldrich) and 100 mL 1-propanol (99.9\%, Fisher Scientific), was introduced into the reactor by an HPLC pump (Series I+, Scientific System Inc.), which could also monitor the total pressure in the reactor. The pressure within the reactor was controlled by a back pressure regulator (KPB series, Swagelok) that was connected at the outlet of reactor. The reactor pressure was fixed at 33 bar for all the experiments performed in this study. Pure $\mathrm{H}_{2}$ (Airgas, UHP grade) was supplied from a high delivery pressure regulator (Airgas) to the reactor through 8 feet of capillary tubing (0.002-inch ID, Valco Instrument, Inc.). The $\mathrm{H}_{2}$ flow rate was calibrated in separate experiments as a function of the cylinder outlet pressure and pressure drop across the capillary tube. For a typical experiment, the liquid flow rate was set as $0.2 \mathrm{ml} / \mathrm{min}$, while the $\mathrm{H}_{2}$ flow rate was $20 \mathrm{ml} / \mathrm{min}$ (STP). The ratio of liquid and gas flow rates was kept constant. A bubble meter at the reactor exit was used to check that the $\mathrm{H}_{2}$ flow rates were maintained.

The catalyst samples (between 0.025 and $0.24 \mathrm{~g}$, depending on the desired range of space velocities to be tested) were packed into the middle portion of the reactor and held in place by glass wool. An inert glass tube was placed downstream from the catalyst in order to prevent the catalyst bed from moving due to the reactant flow and to minimize the open volume of the reactor. Prior to rate measurements, each catalyst was pretreated by heating to $250^{\circ} \mathrm{C}$ in 1 bar of flowing $\mathrm{H}_{2}$ for $30 \mathrm{~min}$. Fresh samples were used for each experiment at a specified reaction condition. 
The reaction products were collected at room temperature and immediately injected into a GC-MS (QP-5000, Shimadzu) for analysis using a syringe. The GC-MS was equipped with an HP-Innowax capillary column (Agilent Technologies). Both liquid- and gas-phase products were examined, but the gas-phase products were found to consist of only $\mathrm{H}_{2}$ and solvent vapor under the conditions of this study. Product selectivities were quantified using solutions with known concentrations of HMF, DMF, dimethyl-tetrahydrofuran (DMTHF), 2-hexanone, 2-hexanol, and 2,5-hexandione (all purchased from Sigma Aldrich). For quantification of other furan-based, intermediate products, the GC sensitivity was assumed to be the same as that for HMF. For openring, ether products, the GC sensitivity was assumed to be the same as 2-hexanone or 2,5hexandione. The typical run time for each experiment was $3 \mathrm{~h}$, and each GC sample analysis time was $30 \mathrm{~min}$. Because all of the catalysts underwent deactivation to some extent, the data which we refer to as "initial performance" were typically chosen from the second or third measurement (40 to 60 min after starting the reaction).

In order to further characterize the DMF reaction kinetics and the distribution of products formed from DMF, experiments were also performed with a mixture of $0.76 \mathrm{~g}$ DMF and $100 \mathrm{~mL}$ of 1-propanol as the feed. The molar concentration of DMF in this case is the same as that used in the HMF experiments. No reaction was observed in the absence of a catalyst under the conditions of this study.

\section{Results}

In the previous HDO study of HMF over Pt/C in 1-propanol, the reaction network was shown to be sequential [9], as indicated in Scheme 1. In this scheme, the HMF (A) first reacts to a group of partially hydrogenated compounds and propyl ether products formed from those compounds (B). Specific products that were formed include 5-propoxymethyl-2-furanmethanol, 5-propoxymethyl-2-methylfuran (ether-methyl furan), 5-methyl furfural (MF), 5-methyl-2furanmethanol (methyl furfuryl alcohol), and 2,5-bis(hydroxymethyl)furan (BHMF). All of these react further to form DMF (C), which was then converted to over-hydrogenated products (D), mainly DMTHF, 2-hexanone, 2-hexanol, and 2,5-hexandione.

Data which demonstrates this for a Pt/C catalyst are shown in Figure 1. In Figure 1a), we have plotted the conversion as a function of space time, along with the yields of DMF and the sum of compounds listed as B and D. The space times are given as the weight of the metal 
catalyst divided by the volumetric flow rates of the liquid. The data presented here were obtained at $180^{\circ} \mathrm{C}$ and 33 bar but qualitatively similar results were obtained at lower temperatures [9]. The product carbon balance in this example was better than $93 \%$ at all space times. Figure 1a) indicates that the conversion was greater than $50 \%$ for even the shortest times. With increasing space time, the partially hydrogenated compounds, B, decreased steadily while the DMF initially increased, then decreased. A more detailed analysis of the partially hydrogenated compounds is given in Table 1. The over-hydrogenated products, D, are not formed initially but only begin to form at higher space times. These results are a strong indication that this is a series reaction, since there is no hydrogenation of the furan ring or formation of open-ring products before DMF production levels off and begins to decline. Figure 1b) gives a more complete analysis of the major over-hydrogenated products. For Pt/C, these are 1-propoxy-1-methyl-pentane (2propoxyhexane) and 1,4-dipropoxy-1,4-dimethyl-butane (2,5-dipropoxyhexane), which are reductive-etherification products formed by reaction of 1-propanol with 2-hexanone and 2,5hexandione, respectively. Only a small amount of DMTHF was formed, demonstrating that secondary reactions on $\mathrm{Pt}$ give primarily open-ring products. Small amounts $(<5 \%)$ of unidentified products were formed at the highest space times.

Similar experiments were performed on $10-\mathrm{wt} \% \mathrm{Ir} / \mathrm{C}, \mathrm{Pd} / \mathrm{C}, \mathrm{Ni} / \mathrm{C}, \mathrm{Co} / \mathrm{C}$, and $\mathrm{Ru} / \mathrm{C}$, with results shown in Figure 2 through 6 and Table 1. The reaction experiments were again performed at $180^{\circ} \mathrm{C}$ and 33 bar but we varied the amounts of catalyst that were loaded into the reactor in order to achieve high conversions for all the metals. The results for each metal were qualitatively the same in the following ways: 1) The HMF conversions increased with space time, as expected. 2) The partially hydrogenated compounds, B, appear to be the first products formed, generally decreasing with space time except for low HMF conversions. 3) The DMF yields initially increase with space time, then decline. 4) Over-hydrogenated products only begin to form at higher space times and their formation coincides with declining DMF yields.

The results for Ir/C in Figure 2 are the most similar to that of Pt/C. Because the results for Ir are shown to higher space times, the DMF conversion, shown in Figure 2a, is higher and the production of over-hydrogenated products more extensive. The product carbon balance was again greater than $90 \%$ at all space times. The most significant difference between the data for $\mathrm{Pt}$ and Ir is in the products formed from DMF, with the major products shown in Figure 2b). Ringopening products, 2,5-dipropoxyhexane and 2,5-hexanedione, are still majority products but 
significant amounts of DMTHF are also formed. Results for $\mathrm{Pd} / \mathrm{C}$ follow the trend. As shown in Figure 3a), the activity of the $10-w t \% \mathrm{Pd} / \mathrm{C}$ catalyst is slightly lower than that of the $\mathrm{Pt}$ and $\mathrm{Ir}$ catalysts, so that higher space times were needed for high conversion of the HMF. However, ring opening is negligible in the secondary products, Figure 3b), with DMTHF forming almost exclusively. The product carbon balance on $\mathrm{Pd} / \mathrm{C}$ was only $85 \%$ for typical reaction conditions and a significant fraction (as much as 10\%) of the over-hydrogenated products could not be identified. As shown by the data for Ni/C, Figure 4, even higher space times are required for high conversions on Ni. However, the yield of DMF at the optimal space time was reasonably high, greater than 50\%; and the major secondary product was 2,5-hexandione. As with Pd, the product carbon balance was only $85 \%$.

Similar to the case for $\mathrm{Ni}$ catalyst, data for $\mathrm{Co} / \mathrm{C}$, Figure 5, and $\mathrm{Ru} / \mathrm{C}$, Figure 6 , indicate that high space times are needed to achieve high conversions. Also, 2,5-hexandione is the major secondary product. The primary difference between these two metals and the others is the carbon balance was very poor. Only 65 to $75 \%$ of the carbon entering the reactor as HMF could be accounted for in the products.

Catalyst stability for the various metals loosely correlated with the carbon balances observed in reaction. Figure 7 is a plot of the relative HMF conversion, normalized to the initial conversion, as a function of time on stream for the six catalysts, for reaction at $180^{\circ} \mathrm{C}, 33 \mathrm{bar}$, using a constant space time, W/F, of $0.25 \mathrm{~g} \cdot \mathrm{min} / \mathrm{L}$. For these flow conditions, the initial conversions were as follows: $83.4 \%$ for $\mathrm{Pt} / \mathrm{C}, 64.5 \%$ for $\mathrm{Ir} / \mathrm{C}, 36.4 \%$ for $\mathrm{Pd} / \mathrm{C}, 47.0 \%$ for $\mathrm{Ni} / \mathrm{C}$, $36.7 \%$ for $\mathrm{Co} / \mathrm{C}$, and $40.6 \%$ for $\mathrm{Ru} / \mathrm{C}$. The figure shows that deactivation was modest on $\mathrm{Pt}$, Ir, and $\mathrm{Pd}$ and much more severe over $\mathrm{Ni}, \mathrm{Co}$, and $\mathrm{Ru}$. Although some of the differences in deactivation between the catalysts are due to the variations in initial activity, it is still apparent that deactivation was most severe on $\mathrm{Ru}$ and $\mathrm{Co}$, the two catalysts for which the carbon balances were also worst. Therefore, it is likely deactivation results from humin formation on the catalyst and that the missing carbon from the mass balance is depositing onto the catalyst.

To obtain a rough estimate of the amount of carbon that may have deposited on the $\mathrm{Ru}$ and Co catalysts, we assumed an average carbon balance $70 \%$ throughout the reaction and a typical liquid flow rate of $0.2 \mathrm{~mL} / \mathrm{min}$. Based on these assumptions, approximately $0.10 \mathrm{~g}$ of HMF-derived compounds could have deposited onto $0.05 \mathrm{~g}$ catalyst after $3 \mathrm{~h}$. Although this amount is large, it is possible that this much of the reactant was retained on the catalyst, given 
the high surface area and low density of the activated carbon support. Because it is very difficult to weigh the wet catalyst after taking it out of the reactor, it was not possible for us to determine with certainty whether this is the reason for the poor carbon balance but the calculation does explain the deactivation behavior.

\section{Reaction of DMF}

To help support the conclusion that the over-hydrogenated compounds in Figures 1 through 6 result from the reaction of DMF, we investigated the products formed by feeding DMF to the reactor. The experiments were carried out with a solution of DMF in 1-propanol (at the same molar concentration as $\mathrm{HMF}$ in 1-propanol), varying $\mathrm{W} / \mathrm{F}$ over the six catalysts at $180^{\circ} \mathrm{C}$ and a total pressure of 33 bar. The data are summarized in Figure 8. The reaction of DMF in this case differs from the conditions of the sequential reactions for HMF in that water is formed in the HDO reaction to form DMF, while no water was present when DMF was fed to the reactor.

First, there is qualitative agreement between the conversion of DMF in the plots of Figure 8 and the data in Figures 1 through 6. For example, with $\mathrm{Ir} / \mathrm{C}$, the conversion of DMF to secondary products during the reaction of $\mathrm{HMF}$ is high at a space time of $4 \mathrm{~g} \cdot \mathrm{min} / \mathrm{mL}$, a result which is also found when DMF is fed to the reactor at this space time. More importantly, the major products from the reaction of DMF agreed with that obtained as secondary products in the reaction of HMF. For example, significant amounts of 2-propoxyhexane were produced over $\mathrm{Pt} / \mathrm{C}$ from DMF reaction at high space time. High yields of 2,5-dipropoxyhexane were observed with $\mathrm{Ir} / \mathrm{C}$. DMTHF was the primary product formed over $\mathrm{Pd} / \mathrm{C}$. For $\mathrm{Ni} / \mathrm{C}, \mathrm{Co} / \mathrm{C}$ and $\mathrm{Ru} / \mathrm{C}$, ringopening or ring-hydrogenation products were also observed with increasing space time. The major difference between results for the reaction of DMF and HMF is that the yields of 2,5hexandione (and its further reaction product, 2,5-dipropoxyhexane) are lower in the reaction of DMF. This is almost certainly due to the much lower water content in the reactant stream when DMF is fed to the reactor, since the reaction of HMF to DMF produces water and 2,5hexandione is formed by hydrolysis. (Note: Some water was present even in the DMF experiments due to the reaction of 1-propanol to form dipropyl ether, a product that was observed in the GC/MS.)

\section{Kinetic Models}

In an attempt to quantify the differences between the metals, we modeled the reaction of HMF as a series of first-order, sequential reactions. Using the reaction network shown in Scheme 
$1, \mathrm{k}_{1}$ is defined as the rate constant for the reaction $\mathrm{A} \rightarrow \mathrm{B}, \mathrm{k}_{2}$ for $\mathrm{B} \rightarrow \mathrm{C}$, and $\mathrm{k}_{3}$ for $\mathrm{C} \rightarrow \mathrm{D}$. The data in Figures 1 through 6 were then fit to give the rate constants shown in Table 2. Table 2 also reports values for $\mathrm{k}_{3}$, which were obtained for the reaction $\mathrm{C} \rightarrow \mathrm{D}$ from the reaction data for DMF in Figure 8. All of the rate constants should obviously be used for comparison purposes only, because the reaction occurs in a complex, three-phase environment. Also, given that all of the catalysts were prepared with the same weight, not mole, percent metal, comparison of rate constants for the various metals is also only qualitative. It was not possible to include humin formation in the reaction network. First, it should be noticed that there is good agreement between $\mathrm{k}_{3}$ and $\mathrm{k}_{3}$, , providing additional evidence that the reaction is sequential on each of the metal catalysts. The fact that $\mathrm{k}_{3}$ values were slightly higher in some cases can be explained by the presence of water formed from the reaction of HMF and the enhanced rates for ring-opening reactions that the presence of water causes. Second, the $\mathrm{k}_{1}$ values in the table quantify our earlier qualitative conclusion that Pt and Ir catalysts were more active for HMF conversion, while the $\mathrm{Pd}, \mathrm{Ni}, \mathrm{Co}$, and Ru catalysts exhibited much lower rates. The Pt and Ir catalysts also have much higher values for $\mathrm{k}_{3}$, which is not desirable for achieving high yields of DMF. The relatively high yields obtained for DMF over Ni/C, even though the rates for DMF formation are relatively low, result from the fact that $\mathrm{k}_{3}$ is also relatively low. It seems apparent that the optimal catalyst would have a high $\mathrm{k}_{1}: \mathrm{k}_{3}$ ratio.

\section{Discussion}

The most important lesson from the results of the present study is that the reaction network for hydrodeoxygenation of HMF is very similar for all six of the metal catalysts that were studied. Indeed, the shape of the curves for products as a function of residence time are distinct in showing that the reaction is sequential, with DMF formed as an intermediate product. Over-hydrogenated products were not observed at low space times and appear only as the DMF selectivities begin to decline. This indicates that hydrogenation of the furan ring and formation of ring-opened products occur through DMF and do not occur until alcohol and carbonyl functionalities are removed from the HMF. The fact that this reaction is sequential has very important implications since selectivity, not rate, is the crucial issue in the choice of catalyst. All of the metals we studied were effective in forming DMF. Whether the metal catalyst was capable 
of achieving high yields was determined more by its reactivity towards DMF. To achieve higher selectivities, one should target catalysts that are inactive for reactions of DMF.

Although the etherification intermediate compounds are not desired products, our previous study has shown that the formation of these ether products can improve the HDO rate over Pt/C [9]. Since those ether compounds can be further converted to DMF, the yield of the ethers can be simply decreased by increasing space time or reaction temperature.

The sequential nature of the reaction also has important consequences for how catalysts should be characterized. For example, if catalysts are simply compared by analyzing the products after a fixed time in a semi-batch reactor, incorrect conclusions may be reached if the reaction time is near the optimum value for one catalyst and past the optimum for another. For example, the present work suggests that reports of poor selectivity with Pt are likely to be caused, at least in part, by the high activity of Pt. Previous batch reactor measurements implied that Pt is not a selective catalyst, whereas it was the most selective (for DMF) of the metals examined in the present flow-reactor study.

Catalyst stability may also play an important role in the yields observed on different metals. For example, among the pure metals, Ru has been reported to be one of the more selective metals [6], much better than Pt [7]. As discussed above, it seems likely that poor selectivity with Pt is at least partially due to the high activity and good stability, which leads to high rates for the reaction of DMF to form other products. On the other hand, Ru was observed to undergo severe deactivation in our study, preventing further reaction of DMF. Therefore, poor stability may be responsible for some previous reports from semi-batch studies that indicated $\mathrm{Ru}$ was the most selective of the pure metals [6].

The various metals did show differences for whether DMF reacts via furan ringhydrogenation or ring-opening. This can probably be explained by the relative adsorption energies of furan rings on the various metal surfaces. For example, it has been argued that [11] the furan ring is strongly absorbed on $\mathrm{Ni}$, which in turn promotes the weakening of the $\mathrm{C}-\mathrm{O}$ bond, leading to ring-opening. On $\mathrm{Pd}$, the interaction is weaker and ring-hydrogenation is preferred.

While we did not examine solvent effects in the present study, the choice of solvent is clearly an important variable in these reactions. In a previous publication from our laboratory [9], HDO rates and selectivities over Pt/C were found to be better with alcohols than with the nonpolar solvent, toluene. On the other hand, work from other laboratories has shown that water 
tends to promote ring-opening reactions [12]. For these reasons, the present work focused on using alcohols as the solvent.

It seems apparent that understanding the reaction network for HDO of HMF is critical for catalyst characterization and for the discovery of new materials. Because the most selective materials reported in the literature for the HDO reaction of HMF are bimetallic catalysts [7,1318], it will be interesting to see whether the reaction on these materials is again sequential or whether it would be better to describe these materials in terms of parallel reaction network. Future work in our laboratory will attempt to address this question with these other types of catalysts.

\section{Conclusions}

The hydrodeoxygenation of HMF to DMF occurs via a sequential reaction network on $\mathrm{Pt}$, $\mathrm{Ir}, \mathrm{Pd}, \mathrm{Ni}, \mathrm{Co}$, and $\mathrm{Ru}$, with the selectivity determined by the ratio of rates for the reaction of DMF to over-hydrogenated products and the formation of DMF. While all of the metals initially formed DMF from the HMF, DMF was hydrogenated to different products over the different metals. Catalyst stabilities were also metal dependent. The results indicate that the selectivities to $\mathrm{DMF}$ are a strong function of the type of reactor used to make the measurements.

\section{Acknowledgement}

We acknowledge support from the Catalysis Center for Energy Innovation, an Energy Frontier Research Center funded by the U.S. Department of Energy, Office of Science, Office of Basic Energy Sciences under Award no. DE-SC0001004.

\section{References}

[1] T. Wang, M. Nolte, B. Shanks, Green Chem. 16 (2014) 548.

[2] M. Dashtban, A. Gilbert, P. Fatehi, R. Soc. Chem. Adv. 4 (2014) 2037.

[3] A. Torres A, P. Daoutidis, M. Tsapatsis, Energ. Environ. Sci. 10 (2010) 1560.

[4] M. Papachristos, J. Swithenbank, G. Priestman, S. Stournas, P. Polysis, E. Lois, J. Inst. Energy. 64 (1991) 113.

[5] C. Williams, C. Chang, P. Do, N. Nikbin, S. Caratzoulas, D. Vlachos, R. Lobo, W. Fan, P. Dauenhauer, ACS Catal. 2 (2012) 935. 
[6] L. Hu, X. Tang, J. Xu, Z. Wu, L. Lin, S. Liu, Ind. Eng. Chem. Res. 53 (2014) 3056.

[7] G. Wang, J. Hilgert, F. Richter, F. Wang, H. Bongard, B. Spliethoff, C. Weidenthaler, F. Schüth. Nat. Mater. 13 (2014) 294.

[8] B. Saha, C. Bohn, M. Abu-Omar, ChemSusChem. 7 (2014) 3095.

[9] J. Luo, L. Arroyo-Ramírez, R. Gorte, D. Tzoulaki, D. Vlachos, AIChE J. 61 (2015) 590.

[10] J. Tengco, Y. Lugo-José, J. Monnier, J. Regalbuto, Catal. Today. 246 (2015) 9.

[11] S. Sitthisa, D. Resasco, Catal. Lett. 141 (2011) 784.

[12] Y. Nakagawa, M. Tamura, K. Tomishige, ACS Catal. 3 (2013) 2655.

[13] S. Nishimura, N. Ikeda, K. Ebitani, Catal. Today. 232 (2014) 89.

[14] S. Sitthisa, W. An, D. Resasco, J. Catal. 284 (2011) 90.

[15] M. Myint, Y. Yan, J. Chen, J. Phys. Chem. C. 118 (2014) 11340.

[16] J. Lee, Y. Kim, G. Huber, Green Chem. 16 (2014) 708.

[17] Y. Huang, M. Chen, L. Yan, Q. Guo, Y. Fu, ChemSusChem. 7 (2014) 1068.

[18] Y. Zu, P. Yang, J. Wang, X. Liu, J. Ren, G. Lu, Y. Wang, Appl. Catal. B. 146 (2014) 244. 
Table 1. Yields of partially hydrogenated compounds over different metal catalysts at a space time of $0.25 \mathrm{~g} \cdot \mathrm{min} / \mathrm{mL}$

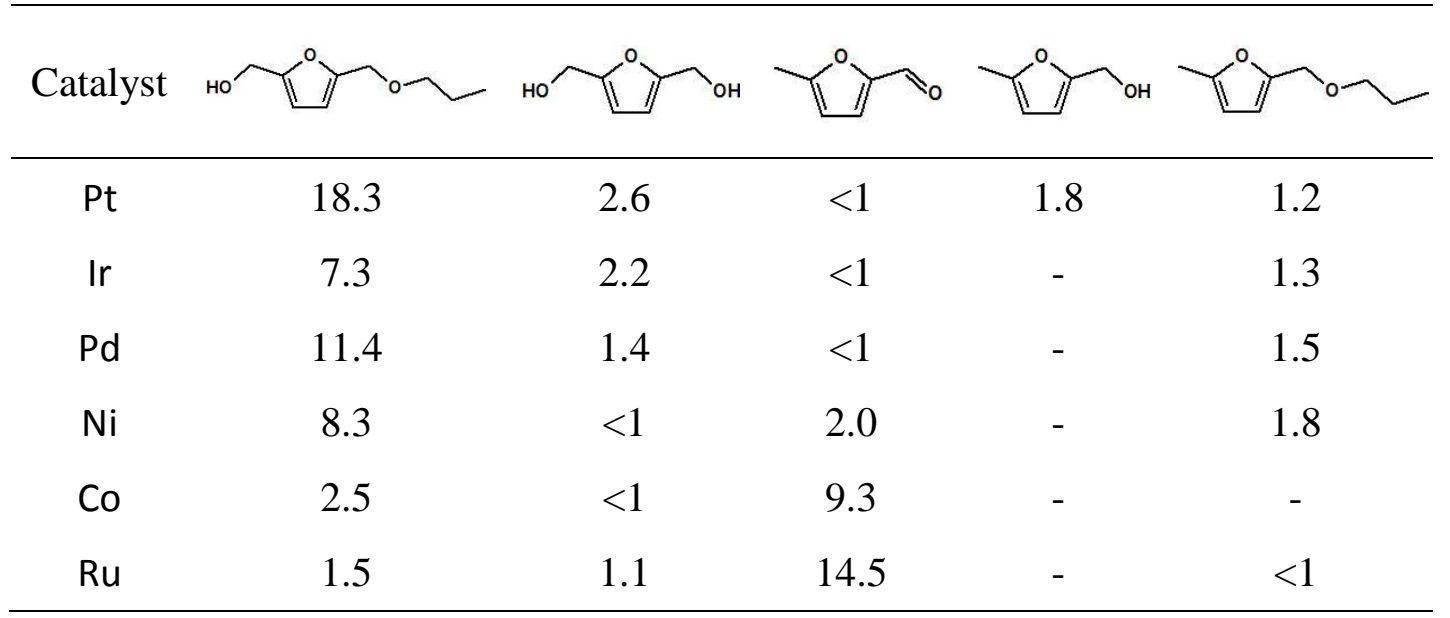


Table 2. Pseudo first-order rate constants for HMF hydrodeoxygenation over the various metal catalysts, for reaction in 1-propanol at $180^{\circ} \mathrm{C}$ and 33 bar.

\begin{tabular}{ccccc}
\hline Catalyst & $\mathrm{k}_{1}\left(\mathrm{~min}^{-1}\right)$ & $\mathrm{k}_{2}\left(\mathrm{~min}^{-1}\right)$ & $\mathrm{k}_{3}\left(\mathrm{~min}^{-1}\right)$ & $\mathrm{k}_{3}{ }^{\prime}\left(\mathrm{min}^{-1}\right)$ \\
\hline $\mathrm{Pt}$ & 5.8 & 9.2 & 1.1 & 1.2 \\
$\mathrm{Ir}$ & 3.5 & 8.8 & 0.56 & 0.48 \\
$\mathrm{Pd}$ & 1.5 & 5.7 & 0.81 & 0.77 \\
$\mathrm{Ni}$ & 1.4 & 3.1 & 0.14 & 0.12 \\
$\mathrm{Co}$ & 1.1 & 3.7 & 0.10 & 0.09 \\
$\mathrm{Ru}$ & 1.0 & 4.3 & 0.16 & 0.14 \\
\hline
\end{tabular}

Note: $\mathrm{k}_{3}$ ' was calculated from rate measurements using DMF as the feed. 


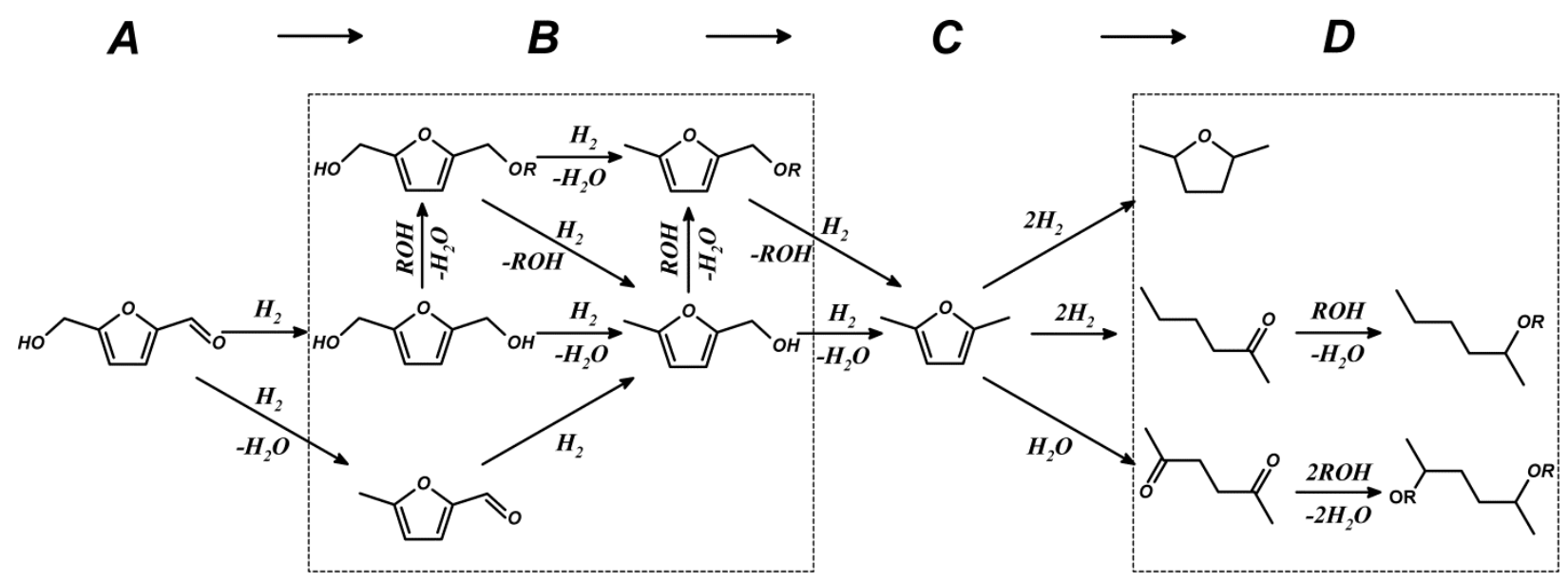

Scheme 1. Reaction network for HMF hydrodeoxygenation using alcohols as solvent. 


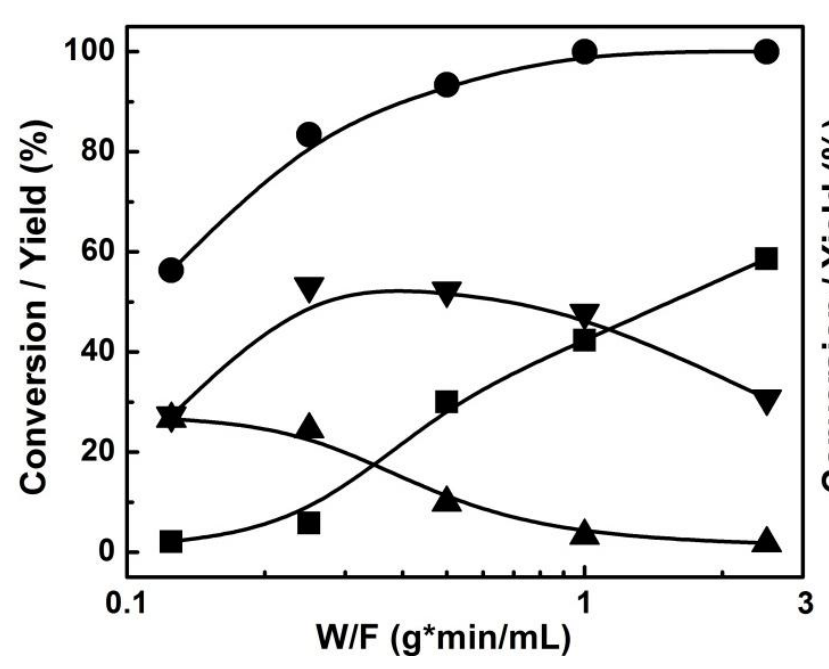

(a)

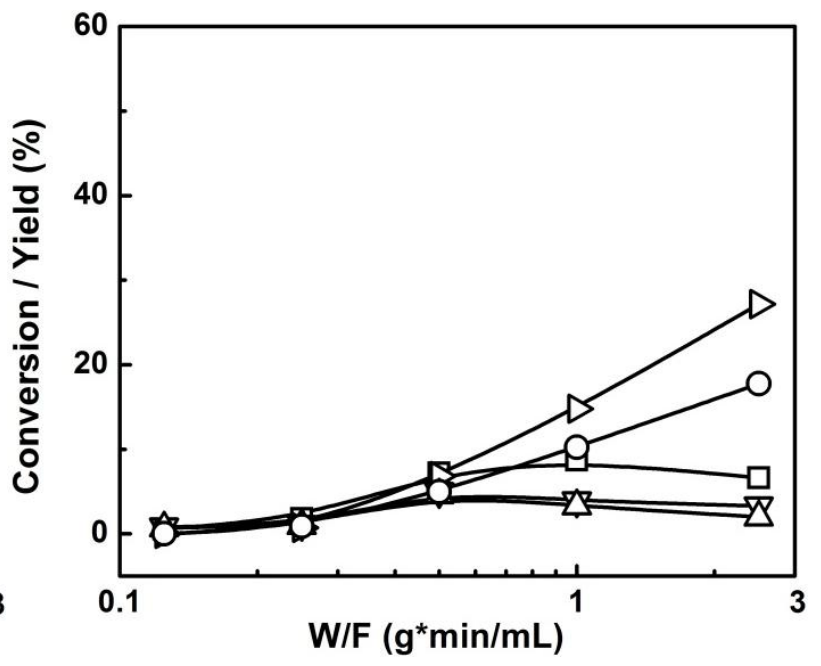

(b)

Fig 1. Conversion and product distribution for the HDO reaction of HMF over a $10-w t \% ~ P t / C$ catalyst as a function of reactor space time. The overall product distribution is given in (a) while a more detailed description of the over-hydrogenated products (product group D) is shown in (b). Reaction conditions: 33 bar and $180^{\circ} \mathrm{C}$. (•) HMF conversion, (A) product group B, ( $)$ DMF, $(\boldsymbol{\square})$ product group D, $(\square)$ DMTHF, $(\nabla)$ 2-hexanone, $(\triangle)$ 2,5hexandione, $(\triangleright)$ 2-propoxyhexane, $(\bigcirc)$ 2,5-dipropoxyhexane 


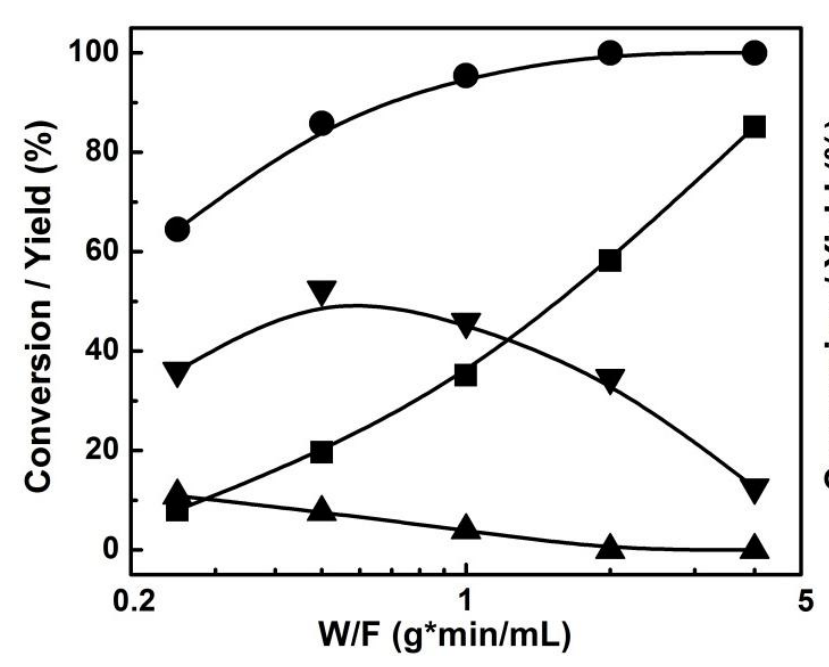

(a)

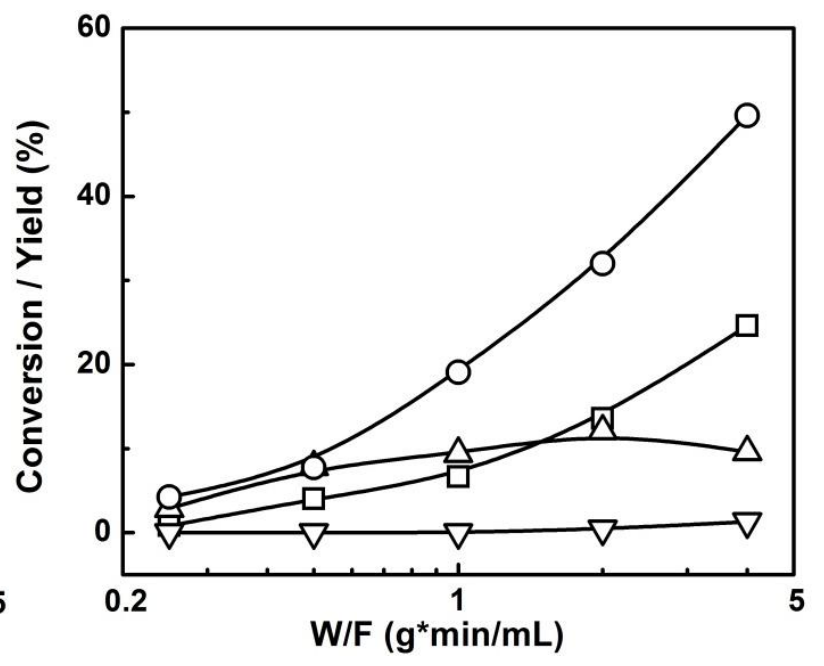

(b)

Fig 2. Conversion and product distribution for the HDO reaction of HMF over a $10-\mathrm{wt} \%$ Ir/C catalyst as a function of reactor space time. The overall product distribution is given in (a) while a more detailed description of the over-hydrogenated products (product group D) is shown in (b). Reaction conditions: 33 bar and $180^{\circ} \mathrm{C}$. (•) HMF conversion, $(\boldsymbol{\Delta})$ product group B, ( $)$ DMF, $(\boldsymbol{\square})$ product group D, $(\square)$ DMTHF, $(\nabla)$ 2-hexanone, $(\triangle)$ 2,5hexandione, $(\triangleright)$ 2-propoxyhexane, $(\bigcirc)$ 2,5-dipropoxyhexane 


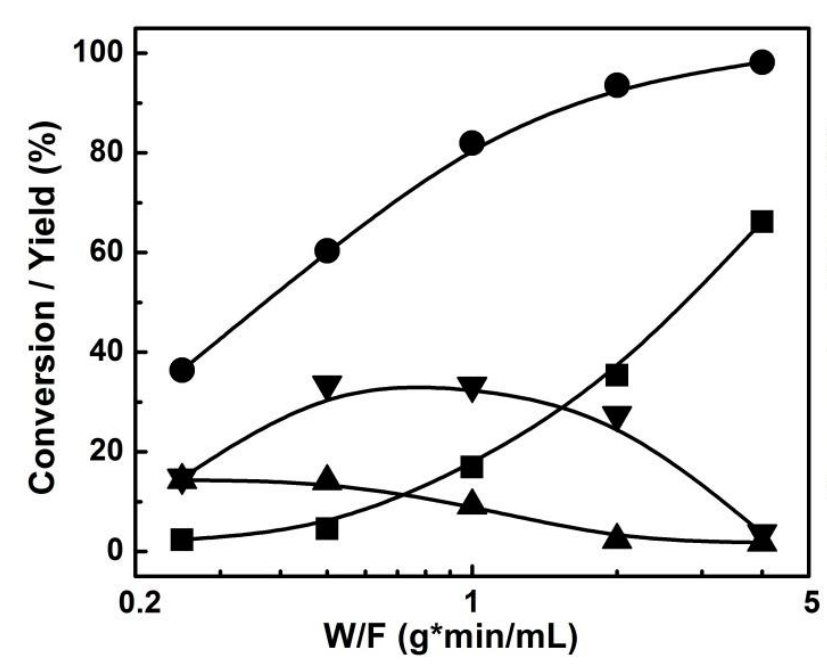

(a)

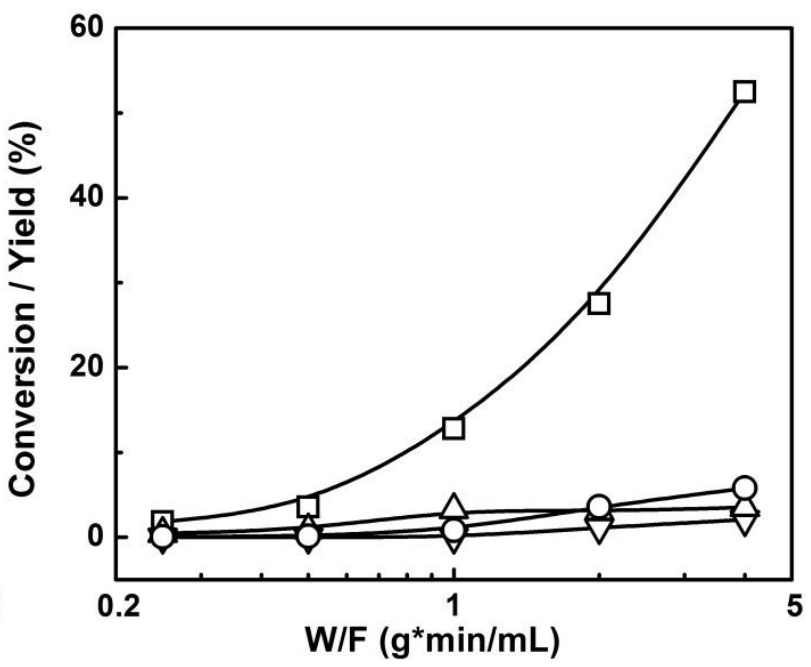

(b)

Fig 3. Conversion and product distribution for the HDO reaction of HMF over a $10-w t \% ~ P d / C$ catalyst as a function of reactor space time. The overall product distribution is given in (a) while a more detailed description of the over-hydrogenated products (product group D) is

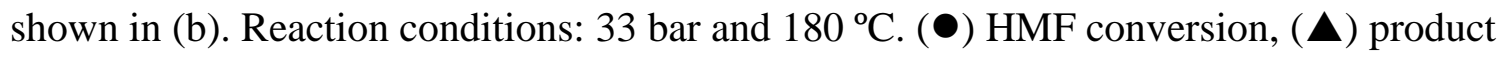
group B, ( $)$ DMF, $(\boldsymbol{\square})$ product group D, $(\square)$ DMTHF, $(\nabla)$ 2-hexanone, $(\triangle)$ 2,5hexandione, $(\triangleright)$ 2-propoxyhexane, $(\bigcirc)$ 2,5-dipropoxyhexane 


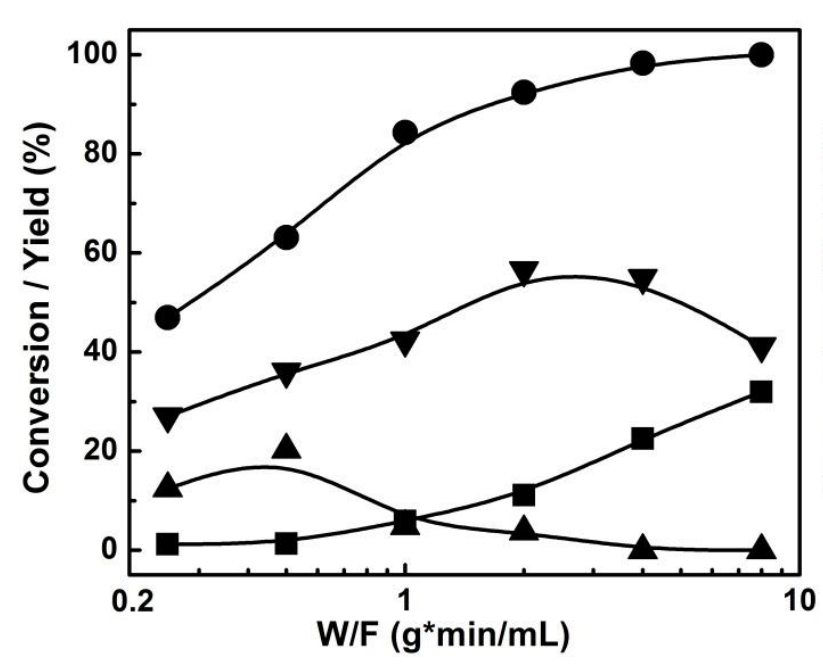

(a)

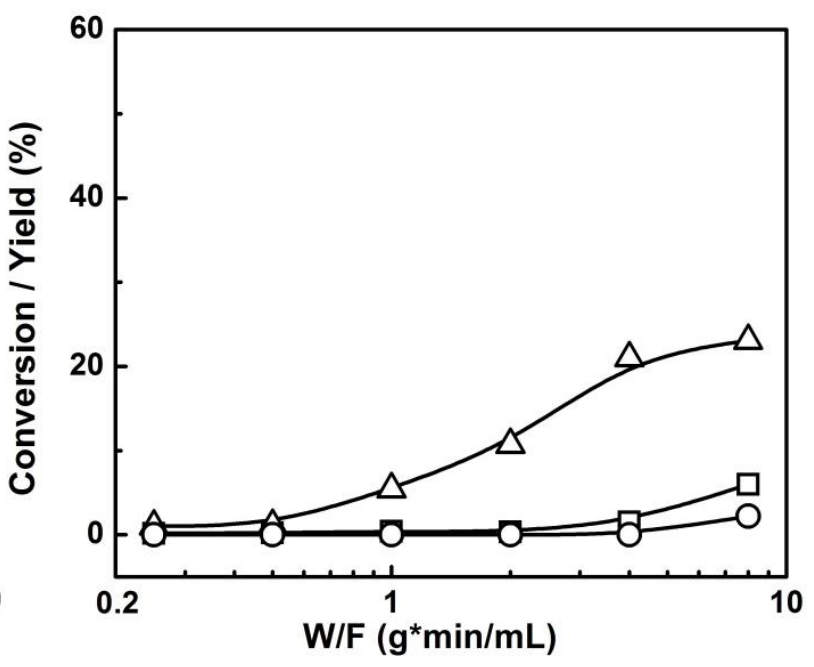

(b)

Fig 4. Conversion and product distribution for the HDO reaction of HMF over a $10-\mathrm{wt} \% \mathrm{Ni} / \mathrm{C}$ catalyst as a function of reactor space time. The overall product distribution is given in (a) while a more detailed description of the over-hydrogenated products (product group D) is shown in (b). Reaction conditions: 33 bar and $180^{\circ} \mathrm{C}$. (•) HMF conversion, (A) product group B, ( $)$ DMF, $(\boldsymbol{\square})$ product group D, $(\square)$ DMTHF, $(\nabla)$ 2-hexanone, $(\triangle)$ 2,5hexandione, $(\triangleright)$ 2-propoxyhexane, $(\bigcirc)$ 2,5-dipropoxyhexane 


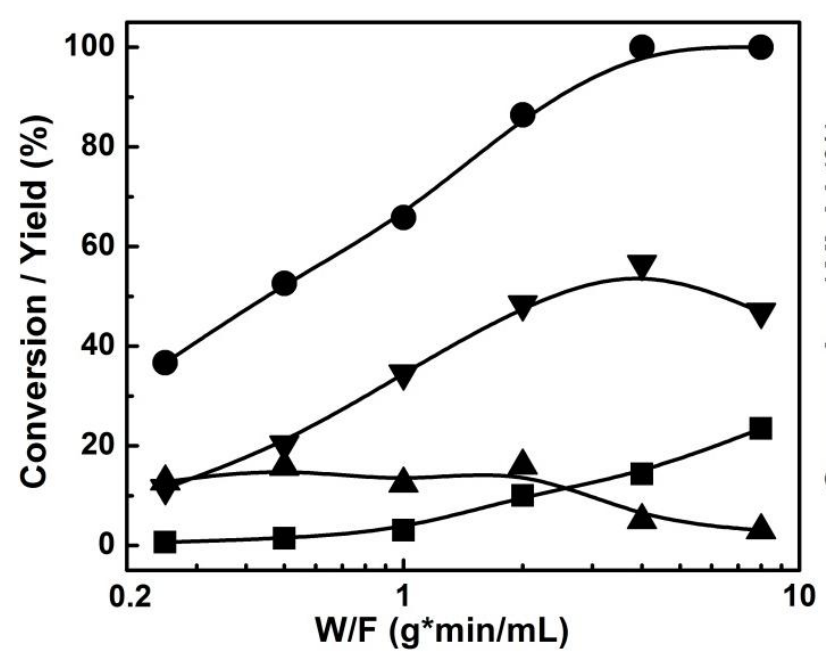

(a)

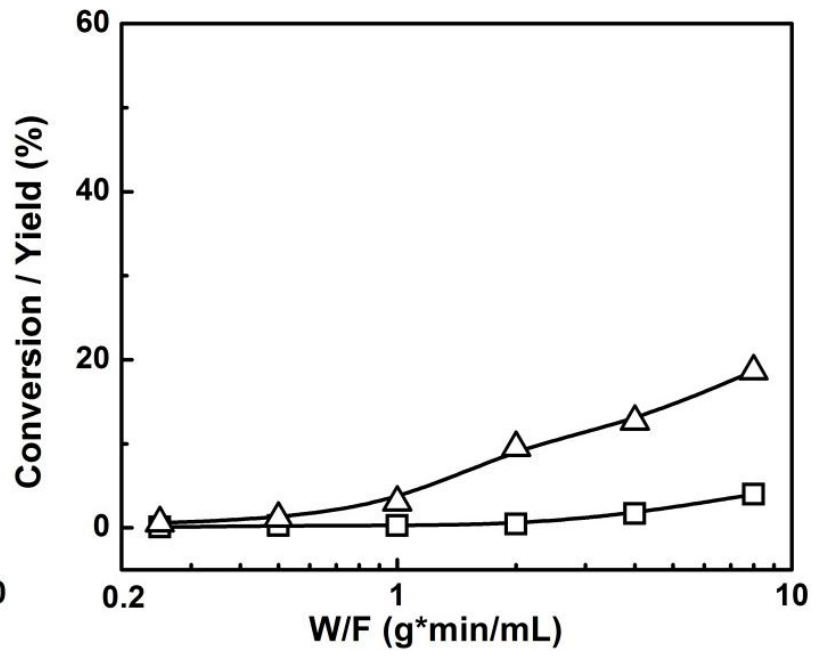

(b)

Fig 5. Conversion and product distribution for the HDO reaction of HMF over a $10-\mathrm{wt} \% \mathrm{Co} / \mathrm{C}$ catalyst as a function of reactor space time. The overall product distribution is given in (a) while a more detailed description of the over-hydrogenated products (product group D) is shown in (b). Reaction conditions: 33 bar and $180^{\circ} \mathrm{C}$. (•) HMF conversion, (A) product group B, ( $\boldsymbol{\nabla})$ DMF, $(\boldsymbol{\square})$ product group D, $(\square)$ DMTHF, $(\nabla)$ 2-hexanone, $(\triangle)$ 2,5hexandione, $(\triangleright)$ 2-propoxyhexane, $(\bigcirc)$ 2,5-dipropoxyhexane 


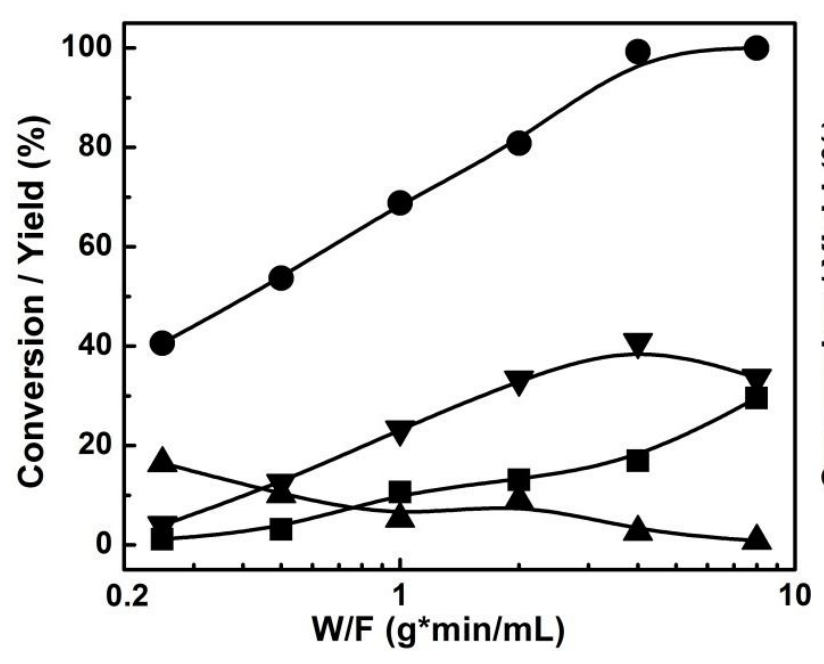

(a)

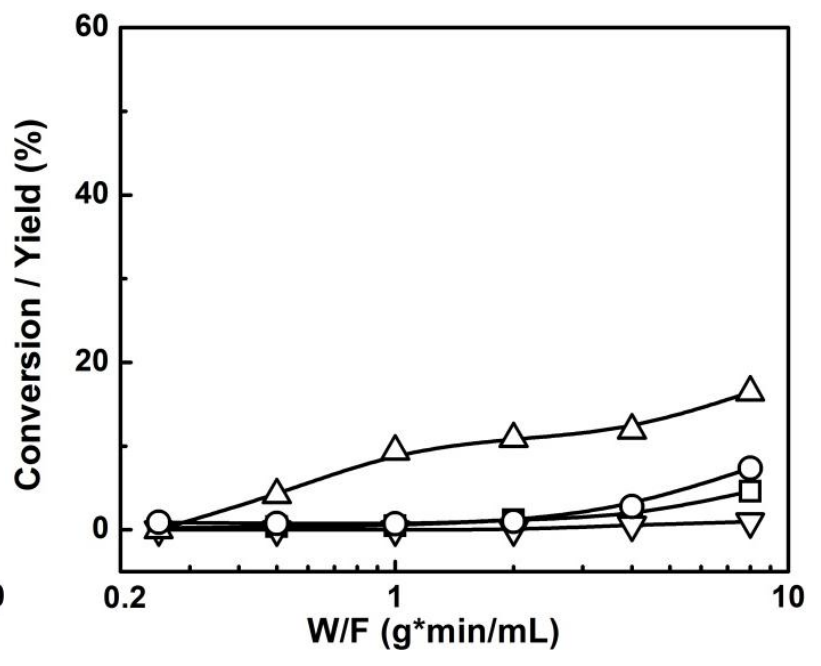

(b)

Fig 6. Conversion and product distribution for the HDO reaction of HMF over a $10-w t \% ~ R u / C$ catalyst as a function of reactor space time. The overall product distribution is given in (a) while a more detailed description of the over-hydrogenated products (product group D) is

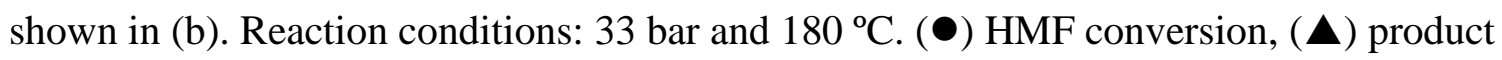
group B, ( $\boldsymbol{\nabla})$ DMF, $(\boldsymbol{\square})$ product group D, $(\square)$ DMTHF, $(\nabla)$ 2-hexanone, $(\triangle)$ 2,5hexandione, $(\triangleright)$ 2-propoxyhexane, $(\bigcirc)$ 2,5-dipropoxyhexane 


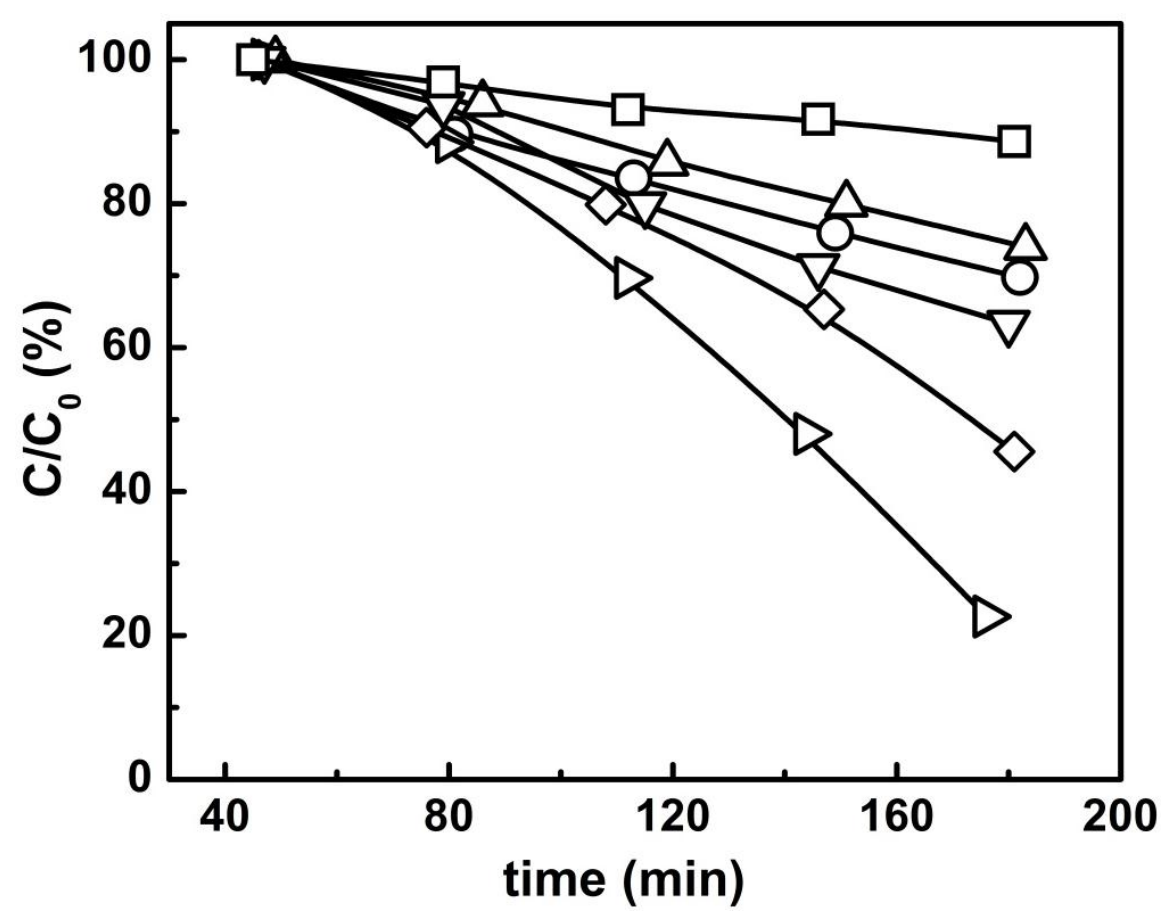

Fig. 7 Normalized conversions for HMF hydrodeoxygenation over each of the six metal catalysts as a function of measurement time. Reaction condition: $\mathrm{W} / \mathrm{F}=0.25 \mathrm{~g} \cdot \mathrm{min} / \mathrm{mL}$, 33 bar and $180^{\circ} \mathrm{C} .(\square) \mathrm{Pt} / \mathrm{C},(\triangle) \mathrm{Ir} / \mathrm{C},(\bigcirc) \mathrm{Pd} / \mathrm{C},(\nabla) \mathrm{Ni} / \mathrm{C},(\diamond) \mathrm{Co} / \mathrm{C},(\triangleright) \mathrm{Ru} / \mathrm{C}$ 


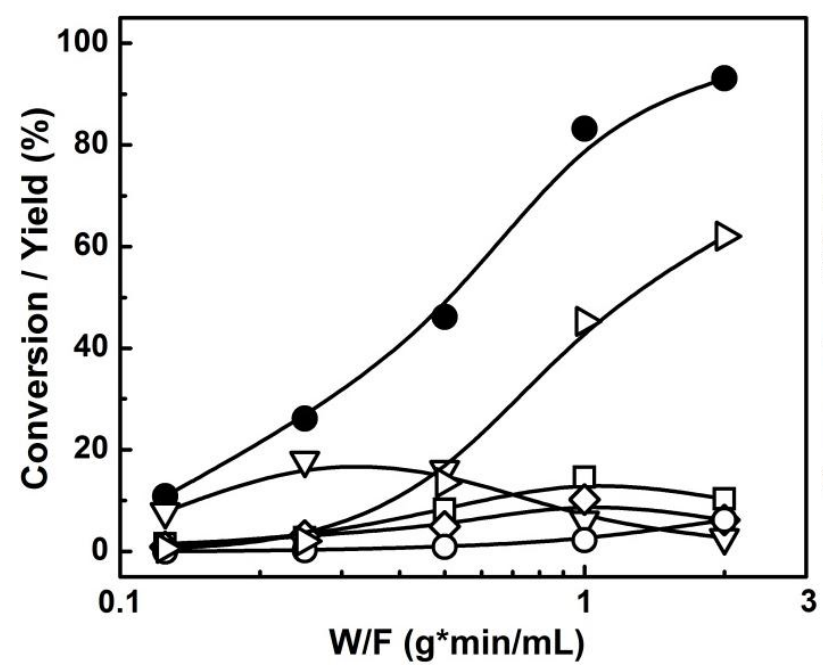

(a) $10 \mathrm{wt} \% \mathrm{Pt} / \mathrm{C}$

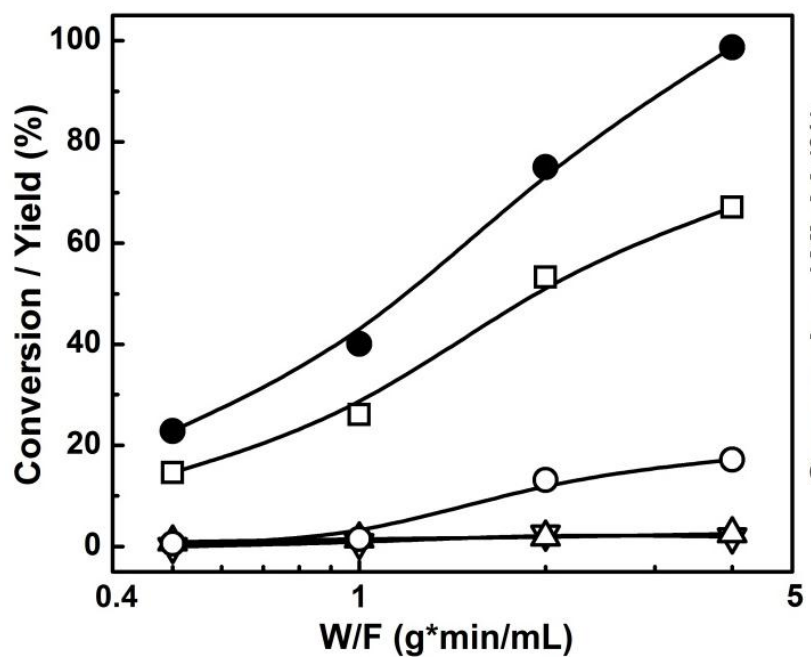

(c) $10 \mathrm{wt} \% \mathrm{Pd} / \mathrm{C}$

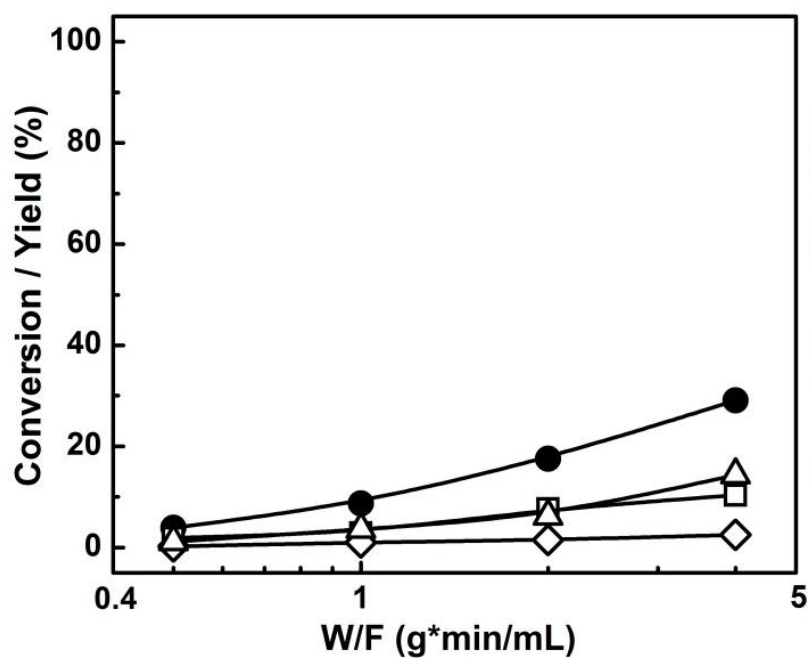

(e) $10 \mathrm{wt} \% \mathrm{Co} / \mathrm{C}$

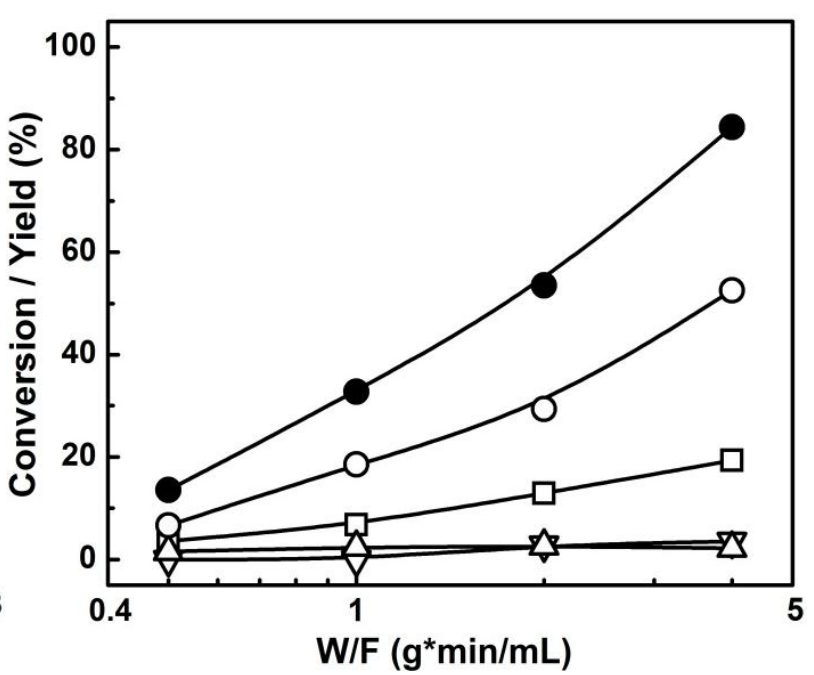

(b) $10 \mathrm{wt} \% \mathrm{Ir} / \mathrm{C}$

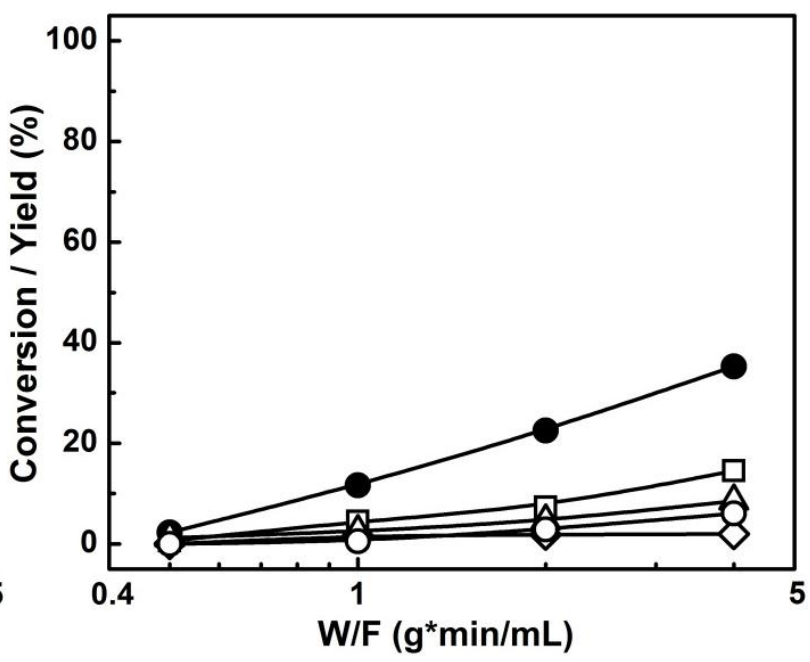

(d) $10 \mathrm{wt} \% \mathrm{Ni} / \mathrm{C}$

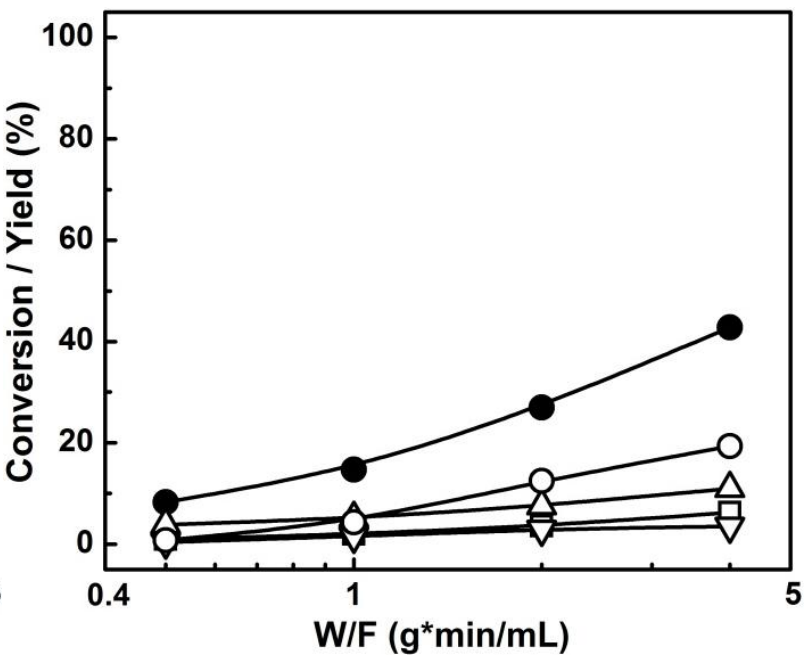

(f) $10 \mathrm{wt} \% \mathrm{Ru} / \mathrm{C}$ 
Fig. 8 Conversion and product distributions for the reaction of DMF in 1-propanol over the various metal catalysts. Reaction condition: 33 bar and $180^{\circ} \mathrm{C}$. a) $10-w t \% \mathrm{Pt} / \mathrm{C}$; b) $10-w t \%$ Ir/C; c) 10-wt\% Pd/C; d) 10-wt\% Ni/C; e) 10-wt\% Co/C; f) 10-wt\% Ru/C. (•) DMF conversion, $(\square)$ DMTHF, $(\nabla)$ 2-hexanone, $(\diamond)$ 2-hexanol, $(\triangle)$ 2,5-hexandione, $(\triangleright)$ 2propoxyhexane, (O) 2,5-dipropoxyhexane 